\title{
Aortopulmonary collateral flow volume affects early postoperative outcome after Fontan completion: A multimodality study
}

\author{
Lars Grosse-Wortmann, MD, ${ }^{\text {a,b }}$ Christian Drolet, MD, ${ }^{\text {a }}$ Andreea Dragulescu, MD, PhD, ${ }^{\text {a }}$ \\ Yasuhiro Kotani, MD, ${ }^{\mathrm{a}}$ Rajiv Chaturvedi, MD, ${ }^{\mathrm{a}}$ Kyong-Jin Lee, MD, ${ }^{\mathrm{a}}$ Luc Mertens, MD, PhD, ${ }^{\mathrm{a}}$ \\ Katherine Taylor, MD, ${ }^{a}$ Gustavo La Rotta, MD, ${ }^{a}$ Glen van Arsdell, MD, ${ }^{a}$ Andrew Redington, MD, ${ }^{a}$ and \\ Shi-Joon Yoo, MD, $\mathrm{PhD}^{\mathrm{a}, \mathrm{b}}$
}

Objective: Aortopulmonary collaterals are a frequent phenomenon in patients after bidirectional cavopulmonary connection. The aortopulmonary collateral flow volume can be quantified using cardiac magnetic resonance imaging. However, the significance of aortopulmonary collateral flow for the postoperative outcome after total cavopulmonary connection is unclear and was sought to be determined.

Methods: The data from 33 patients were prospectively studied with cardiac magnetic resonance, echocardiography, and cardiac catheterization before the total cavopulmonary connection operation. The early postoperative outcomes after total cavopulmonary connection completion were recorded.

\begin{abstract}
Results: Aortopulmonary collateral flow was $1.59 \mathrm{~L} / \mathrm{min} / \mathrm{m}^{2} \pm 0.65 \mathrm{~L} / \mathrm{min} / \mathrm{m}^{2}$ (range, $0.54 \mathrm{~L} / \mathrm{min} / \mathrm{m}^{2}-3.34$ $\mathrm{L} / \mathrm{min} / \mathrm{m}^{2}$ ), constituting $43 \% \pm 13 \%$ (range, $12-87 \%$ ) of pulmonary blood flow and $35 \% \pm 12 \%$ (range, $11-62 \%$ ) of the cardiac index, resulting in a pulmonary blood flow/systemic blood flow ratio of $1.06 \pm 0.17$ (range, 0.79-1.55). The aortopulmonary collateral flow correlated with pulmonary blood flow/systemic blood flow ratio $(r=0.69, P<.0001)$, oxygen saturation $(r=0.42, P=.018)$, and cardiac index $(r=0.53$, $P=.002$ ). Of the 36 patients, 24 underwent fenestrated total cavopulmonary connection during the study period. The aortopulmonary collateral flow, relative to the cardiac index, correlated with the duration of hospital stay $(r=0.48, P=.02)$ and pleural drainage $(r=0.45, P=.03)$. Patients whose pleural drainage lasted 1 week or less had less aortopulmonary collateral flow before the Fontan operation than those with a longer period until chest tube removal $\left(1.23 \mathrm{~L} / \mathrm{min} / \mathrm{m}^{2} \pm 0.38 \mathrm{~L} / \mathrm{min} / \mathrm{m}^{2}\right.$ vs $\left.1.73 \mathrm{~L} / \mathrm{min} / \mathrm{m}^{2} \pm 0.76 \mathrm{~L} / \mathrm{min} / \mathrm{m}^{2} ; P=.03\right)$. Compared with a contemporary group of total cavopulmonary connection patients with fenestration in their extracardiac conduit who were studied prospectively, with a similar protocol, the bidirectional cavopulmonary connection had a greater amount of aortopulmonary collateral flow $\left(1.59 \mathrm{~L} / \mathrm{min} / \mathrm{m}^{2} \pm 0.65 \mathrm{~L} / \mathrm{min} / \mathrm{m}^{2}\right.$ vs $1.30 \mathrm{~L} / \mathrm{min} / \mathrm{m}^{2} \pm$ $\left.0.57 \mathrm{~L} / \mathrm{min} / \mathrm{m}^{2}, P=.04\right)$.
\end{abstract}

Conclusions: Patients after bidirectional cavopulmonary connection routinely acquire a large amount of aortopulmonary collateral flow. The hemodynamic consequences of aortopulmonary collateral flow translate into adverse outcomes early after total cavopulmonary connection completion. (J Thorac Cardiovasc Surg 2012;144:1329-36)

The clinical significance of aortopulmonary collaterals (APCs) for patients with functionally single ventricles remains the subject of debate. ${ }^{1-5}$ Our group has recently introduced the quantitative assessment of APC blood flow using cardiac magnetic resonance (CMR). ${ }^{6}$ In retrospective studies, we and others have demonstrated the feasibility of APC flow measurements in patients with bidirectional cavopulmonary connections (BCPCs) and after Fontan-type

\footnotetext{
From the Labatt Family Heart Center ${ }^{\mathrm{a}}$ and Department of Diagnostic Imaging, ${ }^{\mathrm{b}}$ Hospital for Sick Children, University of Toronto, Toronto, Ontario, Canada. Disclosures: Authors have nothing to disclose with regard to commercial support. Received for publication Jan 12, 2012; revisions received Feb 24, 2012; accepted for publication March 16, 2012; available ahead of print April 16, 2012.

Address for reprints: Lars Grosse-Wortmann, MD, Labatt Family Heart Centre, Hospital for Sick Children, 555 University Avenue, Toronto, Ontario M5G 1X8, Canada (E-mail: lars.grosse-wortmann@ sickkids.ca). $0022-5223 / \$ 36.00$

Copyright (C) 2012 by The American Association for Thoracic Surgery doi:10.1016/j.jtcvs.2012.03.032
}

operations. ${ }^{7,8}$ APCs were identified as the source of a considerable left-to-right shunt and absorbed a sizable portion of the cardiac output. ${ }^{7}$ The retrospective nature, small sample sizes, and lack of postoperative outcome data in these studies, however, have prevented an examination of the influence of APC flow volume on the early postoperative outcome after the Fontan operation.

The objectives of the present study were to characterize the magnitude and hemodynamic effects of APCs in a representative cohort of BCPC patients and to assess the effect of APC flow on markers of early postoperative outcomes after the Fontan operation.

\section{METHODS}

This was a prospective single-center observational study. After approval by institutional research ethics board and parental informed written consent, patients with a BCPC were included. They were studied at the time they underwent cardiac catheterization as a part of the diagnostic 


\section{Abbreviations and Acronyms \\ $\mathrm{APC}=$ aortopulmonary collateral \\ $\mathrm{CMR}=$ cardiac magnetic resonance \\ $\mathrm{BCPC}=$ bidirectional cavopulmonary connection \\ PVR = pulmonary vascular resistance \\ $\mathrm{Qp} \quad=$ pulmonary blood flow \\ Qs $=$ systemic blood flow \\ $\mathrm{TCPC}=$ total cavopulmonary connection}

evaluation and possible percutaneous intervention before total cavopulmonary connection (TCPC). During the same general anesthesia, all patients underwent CMR imaging, an echocardiography study, and cardiac catheterization. The CMR scan was performed on a 1.5 Tesla magnet (Avanto; Siemens Medical Solutions, Erlangen, Germany) and included phase contrast flow velocity measurements of all great arteries and veins, using the following settings: temporal resolution to allow 25 phases per cardiac cycle, minimum repetition and echo times, flip angle $30^{\circ}$, in-plane pixel size 1 $\mathrm{mm} \times 1 \mathrm{~mm}$, slice thickness of 3 to $4 \mathrm{~mm}$, continued ventilation, and $3 \mathrm{av-}$ erages. A commercially available workstation (Qflow, version 5.2; MEDIS Medical Imaging Systems, Leiden, The Netherlands) was used for flow quantification. The calculation of APC flow was performed as detailed previously. ${ }^{7,8}$ In brief, APC flow was calculated as the difference between pulmonary arterial influx into and pulmonary venous efflux out of the lungs. The total pulmonary blood flow (Qp) was equal to the pulmonary venous return, and the systemic blood flow (Qs) was calculated as the sum of the flow through the superior vena cava and the descending aorta at the level of the diaphragm.

A cine short-axis stack was acquired with the following parameters: temporal resolution to allow 20 phases per cardiac cycle, minimum repetition time and echo time, flip angle $70^{\circ}$, in-plane pixel size 1.3 $\mathrm{mm} \times 1.3 \mathrm{~mm}$, slice thickness of $5 \mathrm{~mm}$ and variable spacing, continued ventilation, 3 averages, parallel imaging (generalized autocalibrating partially parallel acquisition) with an acceleration factor of 2. Standard postprocessing software (Qmass, version 7.2; MEDIS Medical Imaging Systems) was used to quantify the ventricular volumes and mass from the short-axis stack. Both ventricles were contoured as a common chamber, connecting the endocardial contour by way of the ventricular septal defect. If no ventricular septal defect was present on the imaging slice, a very small communication between the ventricles was created "virtually," to allow for inclusion of both cavities in the functionally single ventricular cavity.

A contrast-enhanced magnetic resonance angiographic scan (Figure 1) was obtained in the coronal plane, using gadopentetate dimeglumine (Magnevist; Bayer, Leverkusen, Germany) at a dose of $0.2 \mathrm{mmol} / \mathrm{kg}$ and the following settings: repetition time $2.91 \mathrm{~ms}$, echo time $1.04 \mathrm{~ms}$, flip angle $30^{\circ}$, isotropic voxel size of $1.0 \mathrm{~mm}$ to $1.2 \mathrm{~mm}$, generalized autocalibrating partially parallel acquisition imaging, with an acceleration factor of 3 .

On completion of the CMR examination, the patient was transferred to the adjacent cardiac catheterization laboratory and underwent a limited echocardiogram for the assessment ventricular systolic and diastolic global and regional function, using a GE Vivid 7 or Vivid E9 machine (General Electric Medical Systems, Wauwatosa, Wis). Raw DICOM (Digital Imaging and Communications in Medicine) imaging data were digitally stored and analyzed off-line using commercially available software (EchoPAC, version 110.1.3; General Electric Medical Systems). The parameters of atrioventricular inflow and the tissue Doppler velocities of the lateral and medial atrioventricular annuli were measured. Using 2-dimensional speckle tracking on short-axis cuts acquired at the basal, midventricular, and apical level of the ventricular mass, radial and circumferential strain, basal and apical rotation, and early diastolic untwist rate were measured. Three apical views, the equivalent of the 4-, 3-, and 2-chamber views, were used to assess the global longitudinal strain and strain rate.

Finally, cardiac catheterization was performed in the routine clinical fashion and with similar anesthetic settings. The mean pulmonary arterial and atrial pressures and ventricular end-diastolic pressures were obtained. The pulmonary vascular resistance (PVR) was calculated using the invasive pressure data and the CMR flows, according to the following formula:

$$
\begin{aligned}
\mathrm{PVR}= & (\text { mean pulmonary arterial pressure } \\
& - \text { mean atrial pressure }) / \mathrm{Qp}(\text { sum of pulmonary venous flows }) .
\end{aligned}
$$

Patients who underwent coil embolization of the APCs underwent a follow-up CMR investigation to assess the effect of this intervention on the hemodynamics. The follow-up examination took place immediately before the TCPC operation to use the general anesthetic necessary for surgery on that day. All patients had a fenestrated extracardiac conduit placed. A subgroup of patients underwent a post-TCPC combined CMR/catheterization examination at their percutaneous fenestration closure. The CMR protocol was identical to that at the BCPC stage. In addition, fenestration flow was determined by subtracting the flow in the TCPC pathway above the fenestration from that below it. The demographic and clinical data, including information on the postoperative course, were extracted from the patient charts.

In addition to patients with a previous CMR scan at the BCPC stage, a larger cohort of patients after fenestrated TCPC was studied, using a similar protocol.

\section{Statistical Analysis}

Any 2 groups were compared using Student $t$ test. A paired $t$-test was used to compare the measurements in patients before and after coil occlusion of APCs and before and after Fontan completion. The Pearson correlation coefficient and multiple regression analysis were used to study the association between the different parameters. $P$ value $<.05$ was considered statistically significant.

\section{RESULTS}

A total of 33 patients were enrolled in the present study. The patients' demographic information is summarized in Table 1. Their principal cardiac anatomy included a double inlet left ventricle $(\mathrm{n}=7)$, hypoplastic left heart syndrome $(\mathrm{n}=7)$, tricuspid atresia $(\mathrm{n}=6)$, double outlet right ventricle $(\mathrm{n}=6)$, an unbalanced atrioventricular septal defect $(\mathrm{n}=3)$, a double inlet right ventricle $(\mathrm{n}=1)$, hypoplastic right ventricle $(\mathrm{n}=1)$, and twisted atrioventricular connections $(\mathrm{n}=1)$. The APC flow was greater to the left lung than to the right $\left(0.91 \pm 0.45\right.$ vs $0.69 \mathrm{~L} / \mathrm{min} / \mathrm{m}^{2} \pm 0.38 \mathrm{~L} / \mathrm{min} /$ $\mathrm{m}^{2} ; P=.02$; Figure 2).

The APC flow did not correlate with the age at CMR, age at $\mathrm{BCPC}$, or interval since BCPC. The amount of collateral flow, relative to cardiac output, correlated with oxygen saturation under general anesthesia $(r=0.42, P=.018)$. The APC flow also correlated with the Qp and Qp/Qs ratio $(r=0.62, P=.0002$ and $r=0.69, P<.0001$, respectively; Figure 3). The APC flow to the right lung correlated inversely with antegrade right pulmonary arterial flow $(r=-0.48, P=.0051)$. Similar correlations did not exist for the left and total pulmonary arterial flow. The APC flow correlated with cardiac output, as measured by the 


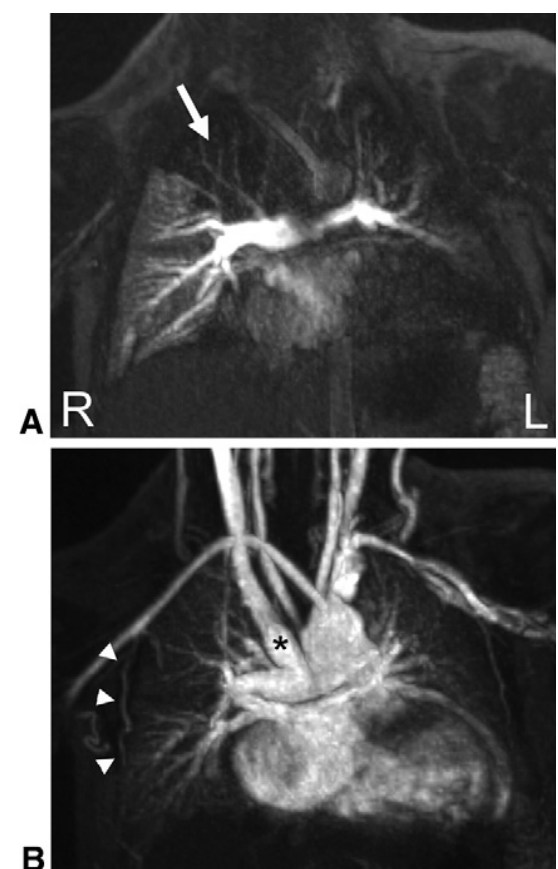

FIGURE 1. Maximum intensity projections of 3-dimensional contrastenhanced magnetic resonance angiographic data set. A, The data set acquired during the first pass perfusion of the lungs demonstrates patchy opacification defects (arrow) caused by dominance of unopacified blood by aortopulmonary collaterals (APCs) over contrast-enhanced blood by the superior vena cava (asterisk in Figure 1,B) and branch pulmonary arteries. B, The systemic arterial phase after the same injection showed a uniform opacification of all lung fields from both pulmonary arterial and APC blood flow, as well as an extensive network of chest wall collaterals (arrowheads), more on the right than on the left, as well as prominent internal mammary arteries. $L$, Left; $R$, right.

ascending aortic blood flow $(r=0.53, P=.002)$. The APC flow did not correlate with the mean pulmonary arterial pressure, PVR, or ventricular end-diastolic pressure. When assessed by echocardiography, the circumferential, radial, and lateral strain and rotation and twist did not correlate with the degree of APC flow. The amount of APC flow, either absolute or relative to cardiac output, did not correlate with the end-diastolic ventricular volume, ejection fraction, ventricular mass, or ventricular mass/volume ratio. The correlation of APC flow with the patients' heart rate $(r=0.32)$ almost reached statistical significance $(P=.071)$. Patients with hypoplastic left heart syndrome had the same amount of APC flow as patients with other diagnoses, and the APC flow did not differ in patients with levocardia vs dextrocardia.

Four patients were examined before and after coil occlusion of APCs (Table 2). The response to this intervention was heterogeneous, and no significant change was seen in the absolute or relative APC flow volume, Qp/Qs, or ventricular end-diastolic volume. Patient 1 had complete occlusion of the left upper and moderate stenosis of the left lower pulmonary vein. In this patient, bilateral coil occlusion of the internal mammary arteries led to a marked reduction in collateral flow to the right lung, but not to the left. In patient 2, there was an increase in absolute and relative APC flow within less than 3 weeks, and patient 4 appeared to benefit from APC occlusion.

Of the 33 patients, 24 had undergone a fenestrated extracardiac tunnel at the last follow-up point. The descriptors of postoperative outcome are listed in Table 1. There were no peri- or early postoperative deaths. Four patients were discharged with chest drains in situ. Two patients underwent additional interventions after TCPC completion, during the same admission: 1 patient received a permanent pacemaker and 1 underwent a series of percutaneous and surgical operations (coil occlusion of APC vessels from the right renal and right subclavian arteries). One patient spent more than 2 months in the intensive care unit and 5 months in the hospital because of a severe cerebral insult. He was excluded from the outcome analysis.

In the remaining patients, the amount of APC flow, relative to cardiac output, correlated with the duration of hospital stay $(r=0.48, P=.02)$ and with the duration of pleural drainage ( $r=0.45, P=.03$ ). Patients whose pleural drainage lasted 7 days or less had less APC flow, both absolute and relative to cardiac output, before the Fontan operation than those with longer pleural drainage $(1.23 \pm 0.38$ vs $1.73 \mathrm{~L} / \mathrm{min} / \mathrm{m}^{2} \pm 0.76 \mathrm{~L} / \mathrm{min} / \mathrm{m}^{2}, P=.025$ and $0.27 \pm$ 0.10 vs $0.40 \mathrm{~L} / \mathrm{min} / \mathrm{m}^{2} \pm 0.16 \mathrm{~L} / \mathrm{min} / \mathrm{m}^{2}, P=.015$, respectively). The differences in pulmonary arterial pressure, PVR, and end-diastolic pressure were not significant between the 2 groups. Patients who developed chylothorax did not have a larger amount of APC flow preoperatively, neither absolute $\left(1.64 \pm 0.84\right.$ vs $1.51 \mathrm{~L} / \mathrm{min} / \mathrm{m}^{2} \pm 0.65$ $\left.\mathrm{L} / \mathrm{min} / \mathrm{m}^{2}, P=.80\right)$, nor relative $(0.37 \pm 0.22$ vs 0.34 $\mathrm{L} / \mathrm{min} / \mathrm{m}^{2} \pm 0.14 \mathrm{~L} / \mathrm{min} / \mathrm{m}^{2}, P=.82$ ) compared with patients who did not develop chylothorax. Also, no significant differences were seen in Qp/Qs $(1.08 \pm 0.23$ vs $1.05 \pm 0.19$, $P=.86)$, PVR $\left(1.31 \pm 0.16\right.$ vs $1.23 \pm 0.51$ Wood units $/ \mathrm{m}^{2}$, $P=.57)$, mean pulmonary arterial pressure $(10.8 \pm 1.5$ vs $10.1 \mathrm{~mm} \mathrm{Hg} \pm 1.7 \mathrm{~mm} \mathrm{Hg}, P=.41$ ) or ventricular enddiastolic pressure $(6.2 \pm 1.9$ vs $6.8 \mathrm{~mm} \mathrm{Hg} \pm 2.4 \mathrm{~mm}$ $\mathrm{Hg}, P=.61)$.

PVR was not predictive of hospital stay, duration of pleural drainage, or central venous pressure. It did correlate inversely with the mixed venous oxygen saturation after the Fontan operation $(r=-0.47, P=.026)$. The preoperative pulmonary arterial pressure did not predict any of the postoperative outcome parameters, including postoperative central venous pressure.

APC flow did not correlate with the oxygen saturation before discharge, in the presence of a fenestration.

Compared with a contemporary group of 23 TCPC patients with a fenestration in their extracardiac conduit who 
TABLE 1. Demographic information, magnetic resonance, catheterization, and echocardiography results, and postoperative information

\begin{tabular}{|c|c|}
\hline Variable & Value \\
\hline \multicolumn{2}{|l|}{ Demographic and clinical data } \\
\hline Gender (male/female) & $26(79 \%$ male $) / 7$ \\
\hline Levocardia/dextrocardia & $28 / 5(85 \%$ levocardia \\
\hline Age at $\mathrm{BCPC}(\mathrm{y})$ & $0.55 \pm 0.20(0.23-1.30)$ \\
\hline Age at CMR (y) & $2.28 \pm 0.70(0.70-3.80)$ \\
\hline Interval since $\mathrm{BCPC}(\mathrm{y})$ & $1.73 \pm 0.63(0.47-2.93)$ \\
\hline $\begin{array}{l}\text { Interval between CMR and } \\
\mathrm{TCPC}(\mathrm{m})\end{array}$ & $5.5 \pm 4.8(0-22.1)$ \\
\hline Duration of CMR (min) & $60 \pm 14(32-86)$ \\
\hline Weight at CMR (kg) & $12.0 \pm 2.0(8.1-17.2)$ \\
\hline Body surface area at CMR $\left(\mathrm{m}^{2}\right)$ & $0.52 \pm 0.06(0.38-0.68)$ \\
\hline Oxygen saturation during CMR $(\%)$ & $87 \pm 4(76-96)$ \\
\hline Heart rate (beats/min) & $101 \pm 12(78-134)$ \\
\hline \multicolumn{2}{|l|}{ Magnetic resonance results } \\
\hline $\begin{array}{l}\text { Ventricular end-diastolic volume } \\
\quad\left(\mathrm{mL} / \mathrm{m}^{2}\right)\end{array}$ & $111 \pm 26(78-232)$ \\
\hline Ventricular mass $\left(\mathrm{g} / \mathrm{m}^{2}\right)$ & $70 \pm 15(45-103)$ \\
\hline Mass/volume (g/mL) & $0.58 \pm 0.12(0.34-1.01)$ \\
\hline Ejection fraction $(\%)$ & $51 \pm 9(36-69)$ \\
\hline Cardiac output $\left(\mathrm{L} / \mathrm{min} / \mathrm{m}^{2}\right)$ & $4.50 \pm 0.85(3.17-6.50)$ \\
\hline $\begin{array}{l}\text { Total pulmonary arterial flow } \\
\left(\mathrm{L} / \mathrm{min} / \mathrm{m}^{2}\right)\end{array}$ & $2.08 \pm 0.63(0.44-3.87)$ \\
\hline $\begin{array}{l}\text { Right pulmonary artery flow, } \\
\text { relative to total pulmonary arterial } \\
\text { flow }(\%)\end{array}$ & $57 \pm 23(0-100)$ \\
\hline $\begin{array}{l}\text { Total pulmonary venous flow (Qp) } \\
\left(\mathrm{L} / \mathrm{min} / \mathrm{m}^{2}\right)\end{array}$ & $3.68 \pm 0.77(2.42-5.65)$ \\
\hline $\begin{array}{l}\text { Right pulmonary vein flow, relative } \\
\text { to total pulmonary venous flow } \\
(\%)\end{array}$ & $51 \pm 11(27-72)$ \\
\hline $\begin{array}{l}\text { Sum of superior vena cava and } \\
\text { descending aorta flow (Qs) } \\
\left(\mathrm{L} / \mathrm{min} / \mathrm{m}^{2}\right)\end{array}$ & $3.50 \pm 0.67(2.50-4.93)$ \\
\hline Qp/Qs ratio & $1.06 \pm 0.17(0.79-1.55)$ \\
\hline APC blood flow to right $\left(\mathrm{L} / \mathrm{min} / \mathrm{m}^{2}\right)$ & $0.69 \pm 0.38(0-1.46)$ \\
\hline APC blood flow to left $\left(\mathrm{L} / \mathrm{min} / \mathrm{m}^{2}\right)$ & $0.91 \pm 0.45(0.13-2.06)$ \\
\hline Total APC blood flow $\left(\mathrm{L} / \mathrm{min} / \mathrm{m}^{2}\right)$ & $1.59 \pm 0.65(0.54-3.34)$ \\
\hline $\begin{array}{l}\text { APC blood flow, relative to } \\
\text { ascending aortic blood flow }(\%)\end{array}$ & $35 \pm 12(11-62)$ \\
\hline $\begin{array}{l}\text { APC blood flow, relative to total } \\
\text { pulmonary blood flow }(\%)\end{array}$ & $43 \pm 13(12-87)$ \\
\hline $\begin{array}{l}\text { Superior vena cava flow, as } \\
\text { percentage of Qs }(\%)\end{array}$ & $59 \pm 11(19-75)$ \\
\hline \multicolumn{2}{|l|}{ Catheterization results } \\
\hline $\begin{array}{l}\text { End-diastolic ventricular pressure } \\
\quad(\mathrm{mm} \mathrm{Hg})\end{array}$ & $6.6 \pm 2.1(3-11)$ \\
\hline $\begin{array}{l}\text { Mean pulmonary arterial pressure } \\
\quad(\mathrm{mm} \mathrm{Hg})\end{array}$ & $10.3 \pm 2.0(7-15)$ \\
\hline Indexed PVR (Wood units $/ \mathrm{m}^{2}$ ) & $1.28 \pm 0.52(0.60-2.81)$ \\
\hline \multicolumn{2}{|l|}{ Echocardiographic results } \\
\hline E/A ratio & $1.19 \pm 0.34(0.85-2.19)$ \\
\hline $\mathrm{E} / \mathrm{E}^{\prime}$ ratio & $10.6 \pm 3.5(6.1-21.8)$ \\
\hline Myocardial performance index & $0.52 \pm 0.10(0.32-0.72)$ \\
\hline
\end{tabular}

TABLE 1. Continued

\begin{tabular}{lc}
\hline \multicolumn{1}{c}{ Variable } & Value \\
\hline Circumferential strain $(\%)$ & $-18 \pm 3(-25-9)$ \\
Radial strain $(\%)$ & $44 \pm 10(-79-81)$ \\
Twist $\left(^{\circ}\right)$ & $7.6 \pm 3.6(-1.7-13.5)$ \\
Post-TCPC outcome $(\mathrm{n}=24)$ & \\
$\quad$ Age at TCPC $(\mathrm{y})$ & $2.79 \pm 0.63(1.78-4.00)$ \\
Duration of inotrope medication (d) & $1.2 \pm 1.1(0-5)$ \\
Length of ICU stay (d) & $1.52 \pm 0.59(1-3)^{*}$ \\
Length of hospital stay (d) & $11.0 \pm 10.7(5-58)^{*}$ \\
Duration of pleural drainage (d) & $15 \pm 14(4-56)$ \\
Incidence of chylothorax (n) & $5(21)$ \\
Last mixed venous oxygen & $65 \pm 6(56-81)$ \\
$\quad$ saturation $(\%) \dagger$ & \\
Last central venous pressure & $15.0 \pm 2.8(11-20)$ \\
$\quad(m m$ Hg) $\dagger$ & $90 \pm 5(79-99)$ \\
Oxygen saturation at discharge $(\%)$ &
\end{tabular}

Data presented as mean \pm standard deviation, with the range in parentheses, or numbers, with percentages in parentheses. $B C P C$, Bidirectional cavopulmonary connection; $C M R$, cardiac magnetic resonance; $Q p$, pulmonary blood flow; $Q s$, systemic blood flow; $A P C$, aortopulmonary collateral; $P V R$, pulmonary vascular resistance; $T C P C$, total cavopulmonary connection; $I C U$, intensive care unit. *One patient spent 70 days in the ICU and 5 months in the hospital because of a neurologic injury and was excluded from the analysis of the ICU and hospital stays. †Before removal of the indwelling central venous catheter.

were also studied prospectively, with a similar protocol, the $\mathrm{BCPC}$ patients had a greater amount of APC flow (1.59 \pm 0.65 vs $\left.1.30 \mathrm{~L} / \mathrm{min} / \mathrm{m}^{2} \pm 0.57 \mathrm{~L} / \mathrm{min} / \mathrm{m}^{2}, P=.04\right)$. The BCPC patients had a lower ventricular mass/end-diastolic volume ratio than did the TCPC patients $(0.58 \pm 0.12 \mathrm{vs}$ $0.64 \mathrm{~g} / \mathrm{mL} \pm 0.13 \mathrm{~g} / \mathrm{mL}, P=.04)$. The difference in the indexed end-diastolic volumes between the 2 groups was not quite significant $\left(123 \pm 32\right.$ vs $111 \mathrm{~mL} / \mathrm{m}^{2} \pm 26 \mathrm{~mL} / \mathrm{m}^{2}$, $P=.06)$. The $\mathrm{Qp} / \mathrm{Qs}$ ratio was similar in the BPCP and Fon$\tan$ patients $(1.05 \pm 0.17$ vs $1.07 \pm 0.23, P=.67)$. Eight patients underwent CMR before and after the Fontan operation (Figure 4). Their hemodynamic data are listed in Table 3. In these patients, the fenestration was patent at the post-Fontan study. The Qp/Qs ratio did not change significantly $(0.94 \pm 0.29$ vs $1.03 \pm 0.23, P=.50)$ nor did the amount of APC flow $\left(1.31 \pm 0.71 \mathrm{vs} 1.36 \mathrm{~L} / \mathrm{min} / \mathrm{m}^{2} \pm 0.76\right.$ $\mathrm{L} / \mathrm{min} / \mathrm{m}^{2}, P=.91$ ) or end-diastolic ventricular volume $\left(123 \pm 33\right.$ vs $\left.123 \mathrm{~mL} / \mathrm{m}^{2} \pm 46 \mathrm{~mL} / \mathrm{m}^{2}, P=.97\right)$.
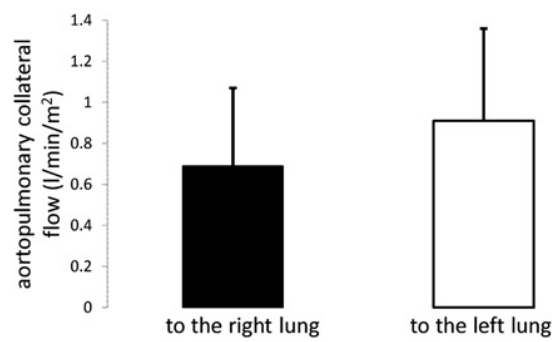

FIGURE 2. Aortopulmonary collateral $(A P C)$ blood flow to the right and left lungs. 


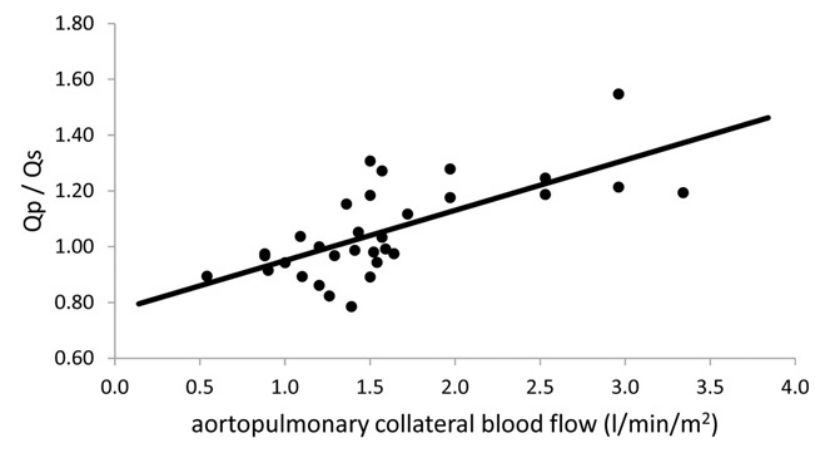

FIGURE 3. Correlation between aortopulmonary collateral (APC) flow and pulmonary to systemic blood flow $(Q p / Q s)$ ratio.

\section{DISCUSSION}

In keeping with previous retrospective studies, we were able to show that BCPC patients carry a substantial amount of APC blood flow. ${ }^{7,8}$ On average, one third (and up to two thirds) of cardiac output travels to the lungs instead of the systemic circulation and more than $40 \%$ (up to $87 \%$ ) of the total pulmonary blood flow originates from APCs. These numbers are very comparable to those recently presented by Glatz and colleagues. 9 Schmitt and colleagues ${ }^{10}$ found an increase in APC flow with exercise. In this regard, it is interesting to note that, in our cohort, a larger cardiac output and greater heart rate correlated with more APC flow. Expectedly, and also consistent with our previous work, ${ }^{7}$ more APC flow resulted in a greater left-to-right shunt. APC flow augmented pulmonary blood flow, and greater APC flow resulted in greater arterial oxygen saturation, indicating that at least some of it participates in gas exchange. Although the results of the present study have confirmed, in principle, as well as in magnitude, the hemodynamic consequences of APCs as described in our previous report, the present study avoids the shortcomings of a retrospective approach. Our results also provide answers to the question of whether APC flow has an effect on the outcomes after Fontan-type operations.

\section{Aortopulmonary Collateral Flow Volume Correlates With Longer Hospital Stay and Prolonged Pleural Effusions After TCPC}

APCs present before the Fontan completion have been suspected to result in unfavorable postoperative hemodynamics. However, the data linking APCs to postoperative outcome are scarce and controversial. ${ }^{1-5,9}$ All but 1 of the prospective studies used the angiographic appearance of APCs as a surrogate for the amount of APC flow. Only Bradley and colleagues ${ }^{1}$ correlated the quantitative APC flow as obtained invasively during the Fontan operation with markers of early postoperative outcome and found no association between the 2 . In the present cohort, patients with more preoperative APC blood flow spent longer in the hospital and experienced from prolonged pleural drainage. Moreover, patients with a shorter drainage duration had less APC flow. These findings are in keeping with the results of a recent retrospective study by Glatz and colleagues. ${ }^{9} \mathrm{Of}$ note, neither the pulmonary arterial pressure nor the PVR obtained during the pre-TCPC catheterization were predictive of the length of hospital stay or of pleural drainage. It has been speculated that APCs might play a more pivotal role in the postoperative outcomes in so-called high-risk Fontan candidates than in the overall functionally singleventricle population, most of whom do reasonably well after the operation. ${ }^{1}$ The precise mechanism through which APCs adversely affect the early postoperative outcomes in these patients is still incompletely understood. Their ventricles appear to tolerate well the increased volume load because of the left-to-right shunt without an increase in enddiastolic pressure or dilatation, at least at rest. ${ }^{10}$ Prakash and colleagues ${ }^{11}$ found a weak association between APC flow and ventricular size in Fontan patients, but the magnitude of the dilation was small. In our cohort, systolic function parameters were not affected by the degree of APC flow. APCs did not overtly increase the PVR or preoperative pulmonary arterial pressure. There is evidence that APC flow diminishes after Fontan completion. Our previous data $^{7}$ and the data from Whitehead and colleagues ${ }^{8}$ indicated that patients with a BCPC are burdened by more APC flow, indexed to the body surface area, than patients after Fontan completion. Prakash and colleagues ${ }^{11}$ found a nonlinear decline in APC flow with time after the Fontan operation. When we compared the amount of APC flow in BCPC patients with that in the cohort of TCPC patients approximately 1 year after their Fontan completion, we found no significant difference between the 2 groups. The same was true for a subgroup of 8 patients who underwent CMR both before and after TCPC completion (Figure 4). Importantly, all these patients had a right-to-left shunt by way of a patent communication between their Fontan pathway and the systemic atrium, although none of the patients who were studied previously either by us ${ }^{7}$ or by Prakash and colleagues ${ }^{11}$ had a fenestration and the interval since Fontan completion was considerably longer in both cohorts than in the present one.

\section{Occlusion of Aortopulmonary Collaterals Might Not Result in Decreased Collateral Blood Flow}

The question whether APCs should be occluded before proceeding to Fontan completion remains the subject of debate. $^{12}$ Although our results seem to indicate that APCs are associated with a worse postoperative outcome, it is unclear whether coiling them is an effective method of reducing the total APC flow. Spicer and colleagues ${ }^{13}$ found a shorter duration of pleural effusions in patients who had undergone APC coil occlusion before the Fontan 
completion. Coil occlusion has been successfully applied to treat prolonged pleural drainage after the Fontan operation. ${ }^{3,14}$ In contrast, in a randomized controlled study that compared CMR and cardiac catheterization in the preBCPC assessment, Brown and colleagues ${ }^{15}$ found a greater rate of collateral occlusion in the catheterization group but no difference in the postoperative outcomes. Whether this experience is transferable to the pre-Fontan stage remains to be seen. In the present study, the response to coil occlusion of the APCs was, at best, heterogeneous. The reason for the lack of response, at least in some of the patients, might be that the internal mammary arteries are not the only culprit with regard to APC flow. Alternative routes such as the bronchial, intercostal, and lateral thoracic arteries, although individually small, can act as a diffuse network to mediate a substantial amount of collateral flow. These vessels often opacify only faintly during a fluoroscopic aortogram and are more difficult to target therapeutically because of a multitude of feeding vessels. Thus, the targeted vessel might not be the main source of APC flow. This might have been the case in 1 patient (patient 2; Table 2) in whom APC flow was even measured greater only 2.5 weeks after the right and left internal mammary artery had been occluded. In a limited number of patients, Bradley and colleagues ${ }^{1}$ found that the reduction in APC flow from coil occlusion faded over time. Although most of the stimulating factors behind APC development in patients with functionally single ventricles remain to be determined, it seems unlikely that these stimuli would abide simply by occluding 2 feeding arteries. Randomized prospective trials are needed to investigate the effect of APC occlusion, based on the results of flow quantification using CMR, on post-Fontan outcomes.

The factors that promote APC formation are incompletely understood. Prakash and colleagues ${ }^{11}$ reported that patients with hypoplastic left heart syndrome have greater APC flow than those with other diagnoses. In our cohort, we found no association between a diagnosis of hypoplastic left heart syndrome or cardiac position within the thorax and APC flow volumes. We were able to show, at least for the right pulmonary artery, that less pulmonary arterial blood flow correlated with more APC flow. Whether lower effective pulmonary blood flow promotes the development of APCs or APCs inhibit effective pulmonary blood flow is not clear. Ascuitto and colleagues ${ }^{16}$ demonstrated energy loss within the effective pulmonary blood flow, because it is disturbed by turbulent APC influx, interfering with the blood flow through the arterial and capillary bed. On average, the left lung receives more APC flow than the right (Figure 2). Although the reason for this is not entirely clear, it might be related to the distribution of pulmonary arterial blood flow, which slightly favors the right lung. It is possible that the left lung recruits more APC flow to balance this preferential

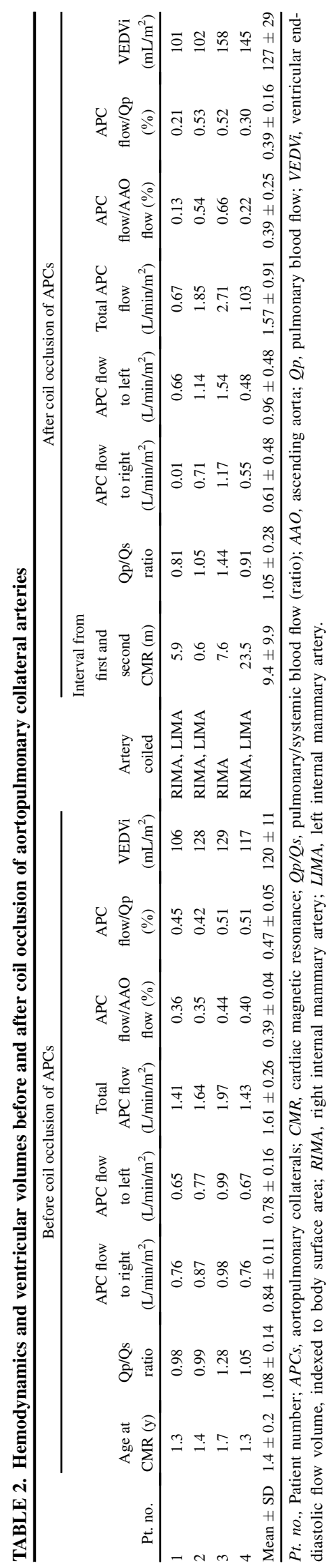


TABLE 3. Hemodynamics and ventricular volumes before and after fenestrated TCPC

\begin{tabular}{|c|c|c|c|c|c|c|c|c|c|c|c|}
\hline \multirow[b]{2}{*}{ Pt. no. } & \multicolumn{5}{|c|}{ Before TCPC completion } & \multicolumn{6}{|c|}{ After TCPC completion } \\
\hline & $\begin{array}{c}\text { Age at } \\
\text { CMR (y) }\end{array}$ & $\begin{array}{c}\text { Interval } \\
\text { between } \\
\text { CMR and } \\
\text { Fontan (m) }\end{array}$ & $\begin{array}{l}\text { Qp/Qs } \\
\text { ratio }\end{array}$ & $\begin{array}{c}\text { APC flow } \\
\left(\mathrm{L} / \mathrm{min} / \mathbf{m}^{2}\right)\end{array}$ & $\begin{array}{c}\text { VEDVi } \\
\left(\mathbf{m L} / \mathbf{m}^{2}\right)\end{array}$ & $\begin{array}{c}\text { Age at } \\
\operatorname{CMR}(y)\end{array}$ & $\begin{array}{c}\text { Interval } \\
\text { from } \\
\text { Fontan to } \\
\text { CMR (m) }\end{array}$ & $\begin{array}{l}\text { Qp/Qs } \\
\text { ratio }\end{array}$ & $\begin{array}{c}\text { APC flow } \\
\left(\mathbf{L} / \mathbf{m i n} / \mathbf{m}^{2}\right)\end{array}$ & $\begin{array}{c}\text { VEDVi } \\
\left(\mathbf{m L} / \mathbf{m}^{2}\right)\end{array}$ & $\begin{array}{c}\text { Fenestration } \\
\text { flow } \\
\left(\mathrm{L} / \mathrm{min} / \mathbf{m}^{2}\right) \\
\end{array}$ \\
\hline 1 & 3.2 & 4.1 & 1.04 & 1.09 & 189 & 4.0 & 5.3 & 1.07 & 0.86 & 190 & 1.19 \\
\hline 2 & 1.8 & 6.6 & 1.31 & 1.50 & 107 & 3.5 & 13.3 & 1.13 & 1.40 & 118 & 1.06 \\
\hline 3 & 1.9 & 0 & 1.05 & 1.85 & 102 & 3.0 & 13.1 & 0.69 & 2.14 & 123 & 1.27 \\
\hline 4 & 2.7 & 7.23 & 0.89 & 0.54 & 119 & 4.0 & 8.8 & 0.88 & 0.20 & 107 & 0.80 \\
\hline 5 & 2.2 & 5.0 & 0.89 & 1.10 & 99 & 3.7 & 12.2 & 1.47 & 1.17 & 76 & 0.56 \\
\hline 6 & 1.8 & 0 & 0.81 & 0.67 & 101 & 2.8 & 12.2 & 1.04 & 1.29 & 104 & 1.36 \\
\hline 7 & 1.7 & 4.1 & 0.94 & 1.54 & 109 & 2.6 & 6.5 & 0.59 & 1.16 & 71 & 1.74 \\
\hline 8 & 2.4 & 0 & 1.44 & 2.71 & 158 & 3.6 & 14.1 & 0.70 & 2.67 & 193 & 2.50 \\
\hline Mean \pm SD & $2.2 \pm 0.5$ & $3.4 \pm 3.0$ & $1.05 \pm 0.22$ & $1.36 \pm 0.70$ & $123 \pm 33$ & $3.4 \pm 0.5$ & $10.7 \pm 3.4$ & $1.03 \pm 0.23$ & $1.36 \pm 0.76$ & $123 \pm 46$ & $1.31 \pm 0.60$ \\
\hline
\end{tabular}

blood flow, as evidenced by the pulmonary venous flow distribution, which is equal between the 2 lungs (Table 1). One patient (patient 1 in Table 2) benefited from APC coil occlusion but only on the right side, which had unobstructed pulmonary venous efflux. APC flow to the left lung remained unchanged (or rapidly recurred) after occlusion of the left internal mammary artery. The case we reported in 2007 to first illustrate the technique of measuring APC blood flow with CMR showed an impressive amount of unilateral APC flow into the lung with significant pulmonary vein stenosis. ${ }^{6}$ These 2 cases led us to speculate that pulmonary vein stenosis might be 1 of the major stimulants for the development of APCs.

\section{Study Limitations}

The present study was limited by a relatively small sample size, which might have been too small to unveil additional risk factors for the development of APCs, as well as their clinical implications. Of the 7 patients who had undergone coil occlusion before their TCPC completion, 4 had

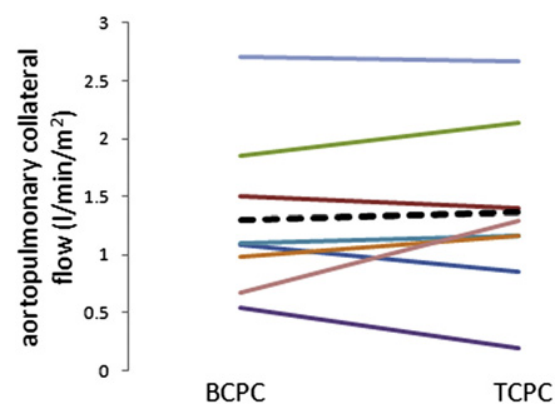

FIGURE 4. Aortopulmonary collateral $(A P C)$ blood flow in 8 patients before and after fenestrated total cavopulmonary connection (TCPC). The dashed line represents the average collateral flow volume. $B C P C$, Bidirectional cavopulmonary connection. had a repeat preoperative CMR study to assess their most recent blood flow. In the remaining 3 , the hemodynamic information from before the coil embolization was used for analysis.

\section{CONCLUSIONS}

Patients after BCPC routinely acquire a large amount of APC flow. The hemodynamic ramifications of APC flow translate into adverse outcomes early after Fontan completion.

\section{References}

1. Bradley SM, McCall MM, Sistino JJ, Radtke WA. Aortopulmonary collateral flow in the Fontan patient: does it matter? Ann Thorac Surg. 2001;72:408-15.

2. Triedman JK, Bridges ND, Mayer JE Jr, Lock JE. Prevalence and risk factors for aortopulmonary collateral vessels after Fontan and bidirectional Glenn procedures. J Am Coll Cardiol. 1993;22:207-15.

3. Kanter KR, Vincent RN, Raviele AA. Importance of acquired systemic-topulmonary collaterals in the Fontan operation. Ann Thorac Surg. 1999;68:969-74.

4. Ichikawa H, Yagihara T, Kishimoto H, Isobe F, Yamamoto F, Nishigaki K, et al Extent of aortopulmonary collateral blood flow as a risk factor for Fontan operations. Ann Thorac Surg. 1995;59:433-7.

5. McElhinney DB, Reddy VM, Tworetzky W, Petrossian E, Hanley FL, Moore P. Incidence and implications of systemic to pulmonary collaterals after bidirectional cavopulmonary anastomosis. Ann Thorac Surg. 2000;69:1222-8.

6. Grosse-Wortmann L, Hamilton R, Yoo SJ. Massive systemic-to-pulmonary collateral arteries in the setting of a cavopulmonary shunt and pulmonary venous stenosis. Cardiol Young. 2007;17:548-50.

7. Grosse-Wortmann L, Al-Otay A, Yoo SJ. Aortopulmonary collaterals after bidirectional cavopulmonary connection or Fontan completion: quantification with MRI. Circ Cardiovasc Imaging. 2009;2:219-25.

8. Whitehead KK, Gillespie MJ, Harris MA, Fogel MA, Rome JJ. Noninvasive quantification of systemic-to-pulmonary collateral flow: a major source of inefficiency in patients with superior cavopulmonary connections. Circ Cardiovasc Imaging. 2009;2:405-11.

9. Glatz AC, Rome JJ, Small AJ, Gillespie MJ, Dori Y, Harris MA, et al. Systemic to pulmonary collateral flow as measured by cardiac magnetic resonance imaging is associated with acute post-Fontan clinical outcomes. Circ Cardiovasc Imaging. Epub 2012 Jan 12

10. Schmitt B, Steendijk P, Ovroutski S, Lunze K, Rahmanzadeh P, Maarouf N, et al Pulmonary vascular resistance, collateral flow, and ventricular function in patients with a Fontan circulation at rest and during dobutamine stress. Circ Cardiovasc Imaging. 2010;3:623-31. 
11. Prakash A, Rathod RH, Powell AJ, McElhinney DB, Banka P, Geva T. Relation of systemic-to-pulmonary artery collateral flow in single ventricle physiology to palliative stage and clinical status. Am J Cardiol. Epub 2012 Jan 3.

12. Banka P, Sleeper LA, Atz AM, Cowley CG, Gallagher D, Gillespie MJ, et al. Practice variability and outcomes of coil embolization of aortopulmonary collaterals before Fontan completion: a report from the Pediatric Heart Network Fontan Cross-Sectional Study. Am Heart J. 2011;162:125-30.

13. Spicer RL, Uzark KC, Moore JW, Mainwaring RD, Lamberti JJ. Aortopulmonary collateral vessels and prolonged pleural effusions after modified Fontan procedures. Am Heart J. 1996;131:1164-8.
14. Kanter KR, Vincent RN. Management of aortopulmonary collateral arteries in Fontan patients: occlusion improves clinical outcome. Semin Thorac Cardiovasc Surg Pediatr Card Surg Annu. 2002;5:48-54.

15. Brown DW, Gauvreau K, Powell AJ, Lang P, Colan SD, Del Nido PJ, et al. Cardiac magnetic resonance versus routine cardiac catheterization before bidirectional Glenn anastomosis in infants with functional single ventricle: a prospective randomized trial. Circulation. 2007;116:2718-25.

16. Ascuitto RJ, Ross-Ascuitto NT. Systematic-to-pulmonary collaterals: a source of flow energy loss in Fontan physiology. Pediatr Cardiol. 2004; 25:472-81.

Access to The Journal of Thoracic and Cardiovascular Surgery Online is reserved for print subscribers!

Full-text access to The Journal of Thoracic and Cardiovascular Surgery Online is available for all print subscribers. To activate your individual online subscription, please visit The Journal of Thoracic and Cardiovascular Surgery Online, point your browser to http://www.mosby.com/itcvs, follow the prompts to activate your online access, and follow the instructions. To activate your account, you will need your subscriber account number, which you can find on your mailing label (note: the number of digits in your subscriber account number varies from 6 to 10). See the example below in which the subscriber account number has been circled:

\section{Sample mailing label}

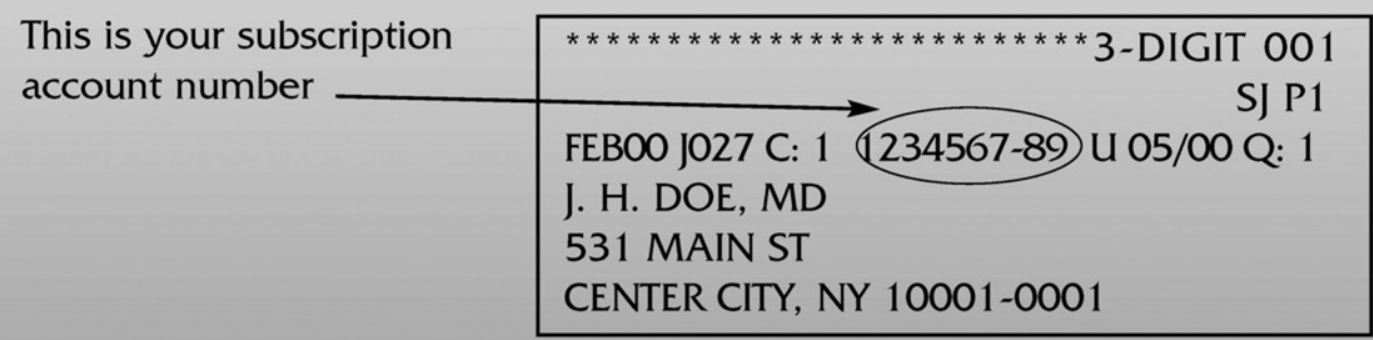

Personal subscriptions to The Journal of Thoracic and Cardiovascular Surgery Online are for individual use only and may not be transferred. Use of The Journal of Thoracic and Cardiovascular Surgery Online is subject to agreement to the terms and conditions as indicated online. 